\title{
Virutal Reality Tourism - Exploring New Possibilities Amid Covid-19 Pandemic
}

\section{OPEN ACCESS}

Volume: 8

Special Issue: 1

Month: February

Year: 2021

P-ISSN: 2321-788X

E-ISSN: 2582-0397

Impact Factor: 3.025

Citation:

Vidya, HN. "Virutal

Reality Tourism

- Exploring New

Possibilities Amid

Covid-19 Pandemic."

Shanlax International

Journal of Arts, Science and Humanities, vol. 8, no. S1, 2021, pp. 230-34.

DOI:

https:/doi. org/10.34293/sijash. v8iS1-Feb.3957

\author{
*Vidya $\mathbf{H}$ N \\ Department of History, Government Arts, Commerce \& \\ Post Graduate College (Autonomous), Hassan District, Karnataka, India \\ *For correspondence (e-mail: vidyasridhara365@gmail.com)
}

\begin{abstract}
This paper explores the tourism trends emerging in post COVID-world. This pandemic was conscientious for an abrupt transformation in the way world travelled. This impulsive impediment in the tourism and hospitality industry was not only unconstructive to the growth of the industry but the imminent influences on future tourism are also looking dim and muted. Virtual Reality has emerged as a new innovative approach to attract viewers though providing them a virtual experience of tourism a tour destination with enhanced technological version. Virtual reality is the new normal in the digital world. People are slowly gaining access to digital tourism experiences through Virtual Reality tourism concept. The increase in virtual reality tourism trend is most welcome thing globally. This trend capitalizes on the use of technology to make viewers experience a touring destination. It includes Virtual Reality tours through which a tourist or viewer can experience a tourist destination, hotel interiors, restaurant interiors, outdoor tourist attractions, shopping sites, archaeological inputs, museums, etc sitting in home. This viewer is made to experience complete visit of the destination through VR head gears and comply with his aspirations of touring. Without being physically present on the tourist site a viewer can become a tourist and see all sites as naturally as a tourister. But this usage of technology driven virtual reality tools are challenged by several factors.
\end{abstract}

Keywords: Indian tourism sector, virutal relaity toruism, Challenges, New poosibilities

\section{Introduction}

Virtual Reality refers to interactive images or videos which enable the viewer to explore the entire 360 degrees of a scene. Unlike a regular image of video which is shot from a view point Virtual Reality production captures every part of the location. Virtual Reality is used in travel industry using specialist cameras rigs and software. The filmed content can then be viewed on either a Virtual Reality headset or a regular computer or a smart mobile device. Virtual Reality has become the most common way in which it is utilized in the marketing tourism industry. Being able to capture tourism destinations in such a memorable and immersive way is a powerful marketing tool. One of the greatest strengths of Virtual Reality is allowing the user to experience the feeling of being there. But regular videos on tourist destination hive information about the place but the 
emotional inclusion of being there is absent in them. Virtual Reality in tourism has the ability to place the user at the $\mathrm{g}$ heart of the scene and makes it easier for them to imagine themselves at the tourist destination.

\section{Virtual Reality Benefits to Tourism and Hospitality Industry}

Virtual Reality benefits the tourism industry in several ways. This technology is evolving at a rapid rate and the uses of Virtual Reality within tourism is expanding along with the technology The main Virtual Reality technologies that are used in the travel industry are Virtual Reality video and Virtual Reality photography. The Virtual Reality tourism video works much like a normal video. They can be viewed on social media or web sites but unlike a regular video the user is able to explore the entire scene while the video is playing. Virtual Reality tourism videos are filmed using specialist cameras also known as Omni directional cameras They film every angle of the destination. After filming it is linked with the audio content and this is how it becomes a virtual reality enable video content.

\section{Virtual Reality Tourism Video Types}

There are two types of Virtual Reality video

1. Monoscopic VR - here videos can be viewed on regular devices including mobiles and computers the viewer can click or drag across the screen in order to rotate the field of view.

2. Stereoscopic VR - captures every angle and gives the cinematic experience .

\section{Virtual Reality has Several Benefits}

As shown in this diagram there are several constructive benefits in adopting Virtual Reality applications.

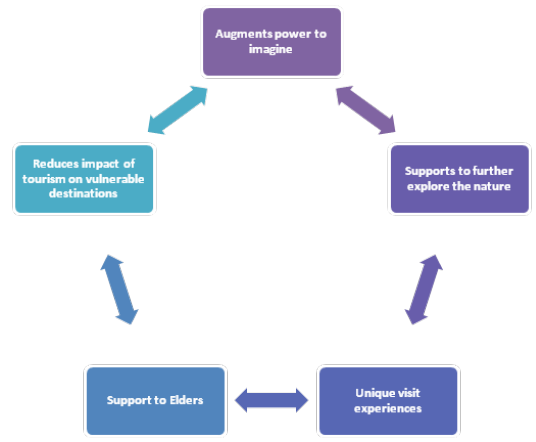

1. Augments power to imagine: Virtual Reality provides the viewer with power to imagine themselves in a tourist destination and offers to understand the complete implications of a tourist destination, its historicity, its cultural journey, its nature flora and fauna etc.

2. Supports to further explore the nature: Virtual Reality enables the viewer to explore the nature surrounding the tourist destination and its ambience in full liberty.

3. Unique visit experiences:Virtual Reality supports viewers with creating memorable and unique visit experiences

4. Support to Elders: Virtual Reality supports elderly people who cannot travel to destinations or who cannot undergo hectic and long flight travel, to experience a destination sitting at home.

5. Reduces impact of tourism on vulnerable destinations: Virtual Reality also reduces impact of tourism on vulnerable destinations. Viewers can support in reducing negative impact on destinations. In another way they also support in reducing negative impact of the carbon foot prints. 


\section{Virtual Reality Usage}

Virtual Reality tools can be used by tourism and hospitality industry to enhance marketing . But this virtual reality tools are best used by

1. Travel Companies and tour operating services

2. Hotels \& restaurants

3. Flight Companies

4. Luxury rail services

5. Luxury Yacht services

6. Ticket Booking Companies

\section{Virtual Reality Global Trends}

In the global scenario the Virtual Reality application have become more popular.

1. Travel companies use Virtual Reality tools to enhance the travel experiences of viewers through Virtual Reality video augmentation process.

2. Virtual hotel tours by travel companies can be made possible. Viewers can analyse the hotel stay accommodation, the interiors, price tags, hotel ambience, room service, lunch services etc.

3. Virtual Reality flight experiences provide viewers flight sharing and viewing through VR head gears.

4. Virtual experiences of Landmark destinations are supportive to tourist who wishes to take up long stay tours.

5. Virtual booking interface services are supportive for enhancing tourist visits and benefits the senior citizens and other such person who wish to get comfortable services.

\section{Virtual Reality \& Multi Disciplinary Study Linkage}

Virtual Reality also has multi disciplinary relationship. The providing of 360 degree viewer experience of a tourist destination is always linked not only with physical explanation of the destination but it comes linked with the entire journey of the place form ancient past to the present. This involves linking with following disciplinary authorities.

- Archaeologists,

- Cultural organization managers,

- Curators,

- Heritage organization professionals,

- Engineers,

- Ethnologists,

- Historians,

- IT specialists

- Museum curators

- Public and private museums curators

- Research Scholars,

- History Students,

\section{Virtual Reality \& Augmentation in Historical Links}

Virtual reality also has several archaeological support which can be extended to visualise the entire destination.

- Visualizing archaeology and heritage in 3D form,

- Virtual museums,

- Virtual, augmented \& mixed reality applications, 
- Serious amusement surrounding,

- Virtual curator vision centers,

- Narrative and Virtual Storytelling,

- Social Networking in cultural heritage,

- Interactive installations in museums and heritage sites,

- Data mining and digital archives,

- Digital Cultural Tourism,

- Digital preservation of historical \& traditional practices,

- Virtual Educational approaches and much more.

\section{Challenges for Applying Virtual Reality Applications}

Virtual Reality is the new normal in the digital world. People are slowly gaining access to digital tourism experiences through Virtual Reality tourism concept. Even though it is a popular medium, this also faces certain challenges. They are listed as below

- Cost aspect

- Management of 3D data documentation

- Lack of technical expertise / trained personnel

- Problems of misinterpretation and misrepresentation

- Standard / bench mark setting

All the above listed points may be of a short duration as nations might find answers to solving these challenges with better visualization strategies and future oriented guidelines released from time to time. As shown in this table

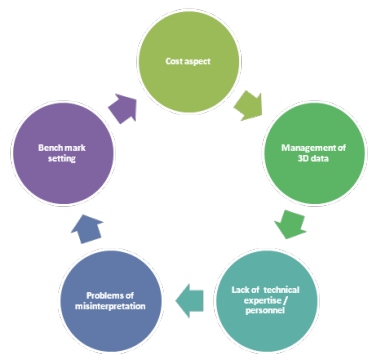

These can further be analysed in detail as follows

\begin{tabular}{|l|l|}
\hline Cost aspect & $\begin{array}{l}\text { Application of digital tools of Virtual Reality tourism is very } \\
\text { expensive and sometimes the expenditure for purchasing digital } \\
\text { tools including cameras and eye gears costs the entire budget of the } \\
\text { organization. }\end{array}$ \\
\hline Management of 3D data & $\begin{array}{l}\text { Virtual Reality tourism comes with challenges of management of } \\
\text { 3 D data which is very complex and intricate. Indian tourism and } \\
\text { hospitality sector need to make arrangements for management of } \\
\text { 3D data , conservation of digital tools , 3D operation technique } \\
\text { operators of digital tools needs to be trained. }\end{array}$ \\
\hline $\begin{array}{l}\text { Lack of technical } \\
\text { expertise / personnel }\end{array}$ & $\begin{array}{l}\text { Virtual Reality tourism is challenged by poor technical expertise. } \\
\text { The technical personnel required for management of virtual reality } \\
\text { data is a bigger challenge. }\end{array}$ \\
\hline
\end{tabular}




\begin{tabular}{|l|l|}
\hline $\begin{array}{l}\text { Problems of } \\
\text { misinterpretation }\end{array}$ & $\begin{array}{l}\text { Virtual Reality tourism suffers from problems of mis-interpretation } \\
\text { and false impression. They are chances of moving away from exact } \\
\text { original history. History can be misinterpreted by juggling historical } \\
\text { facts. India is replete with dynastic confrontations , communal } \\
\text { conflicts, mystified identities etc }\end{array}$ \\
\hline Bench mark setting & $\begin{array}{l}\text { Virtual Reality tourism suffers from a setting a bench mark standard. } \\
\text { There are no average guidelines for 3 D standard management for } \\
\text { Virtual Reality tourism application in Indian tourism sector. There } \\
\text { is a need to include guidelines for framing a standard procedure. }\end{array}$ \\
\hline
\end{tabular}

\section{Conclusion}

With the advent of technologies viewers have been changing the way they live and the way they react to consumption The Virtual Reality tourism experience is a new technology but innovation in technological interventions always come with limited period duration as younger generations adopt to newer innovation the need and the number consuming such content also changes drastically. But of now Virtual Reality has become a reality. The Indian tourism industry needs to gear up in order to match up with global Virtual Reality trends and offer the special tourism experiences to viewers because Indian history and culture is very rich and exceptional.

\section{References}

1. Abbey Vander Hart - Virtual Reality in Archaeology, Visualizing Antiquity Through Modern 2018

2. Asif Ali- Virtual archaeology experiencing the past through technology, research gate 2016

3. Asif Ali- Virtual archaeology experiencing the past through technology, Research Gate 2016

4. Brajesh Sachin -Can Virtual Archaeology Serve India’s Cultural Heritage 2017 CXO Today. Com

5. Carsi C And Others (Ed) - Implementing Beat Practice In Cultural Heritage Visualization Archaeology Diagnostics, 2013

6. Daniel A Gothenburg- Virtual Reality Applications And Implication For Tourism Management 2010

7. Dr .Vidya H N- Visualizing History Through Virtual Archaeology - Emerging Trends IOSR Journal, Special Issue On Historical Inquiry VO1 2 Issue (1) 2018

8. Dr. Vidya H N Assimilating History With Digital Technology Through Virtual Archaeology Tools - New Dimensions, Tumbe International Journal VOL -3 Issue (1) January - April 2020

9. Fredrick Gunnarson- Archaeological Challenges And Digital Possibilities 2018

10.Immanuel Victor and others (Ed) - Digital Heritage And Virtual Archaeology An Approach Through The Frame Work Of International Recommendation 2018

11.Lopez V M- International Guidelines For Virtual Archaeology, 2013

12.Victor Immanuel and Others (Ed) - Digital Heritage And Virtual Archaeology An Approach Through The Frame Work Of International Recommendation 2018.

13.Dr. Vidya H N COVID-19 Pandemic and impact on technology sector - A review of new possibilities 